\title{
An Attempt to Study the Possible Inter-relationships amongst various Selection Criteria of Main Battle Tank through ISM Methodology
}

\author{
Mukesh Bansal \\ IAS, Raipur \\ Chhattisgarh, India
}

\author{
Remica Aggarwal \\ MIT-SOER, MIT- ADT University \\ Pune, India
}

\begin{abstract}
Main battle tanks (MBT) have always been in the heart of all military campaigns and have enabled armies to fight across the full spectrum of war. Countries need to consider the complex interactions between criteria or factors governing the selection of main battle tank. In order to define the interaction among the criteria, this study aims to use the Interpretive Structural modeling (ISM) methodology . The criteria have been determined by consulting a group of experts.
\end{abstract}

\section{Keywords}

Main battle tank; ISM methodology; Armoured vehicles

\section{INTRODUCTION}

Changes in the type of threats in recent years have led to shift in focus on the need for protection against multi-spectral threats. Throughout the history of warfare, materials technologies have had a significant impact on land-combat force capabilities. Armour materials have progressed through improvements in metallic systems and development of advanced, lightweight (low areal density) composite materials. Today, no single material is capable of effectively defeating wide range of threats, and hence, a wide variety of armours have to be developed. Enormous efforts are being put world over on the development of armour materials and systems to provide greater ballistic protection with some increase in weight of the vehicle [1-4]. For providing such a protection, it is essential to create high performance passive, reactive, dynamic, intelligent and active armour technologies with creative armour design concepts.

A tank is a, armoured tracked fighting vehicle designed for front-line combat and combines strong strategic and tactical offensive and defensive capabilities. Tanks were first manufactured during World War I in an effort to break the bloody deadlock of trench warfare. The British Army was the first to field a vehicle that combined three key characteristics: mobility over barbed wire and rough terrain, armour to withstand small arms fire and shrapnel and the firepower required to suppress or destroy machine gun nests and pillboxes. The three traditional factors determining a tank's effectiveness in battle are its firepower, protection/survivability, and mobility. In practical terms, the cost to manufacture and maintain a given tank design is also important in that it determines how many tanks a nation can afford to field. Firepower is the ability of a tank to identify, engage, and destroy a target. Protection is the tank's ability to resist being detected, engaged, and disabled or destroyed by enemy fire. Mobility includes tactical (short range) movement over the battlefield including over rough terrain and obstacles, as well as strategic (long range) mobility, the ability of the tank to be transported by road, rail, sea, or air to the battlefield. It is not possible to maximize firepower, protection and mobility simultaneously. For example, increasing protection by adding armour will result in an increase in weight and therefore decrease mobility; increasing firepower by installing a larger gun will force the designer to sacrifice speed or armour to compensate for the added weight and cost. Therefore with respect to each of the three factors, several tank performance parameters (sub-factors) can be identified e.g rate of fire, maximum firing range, manoeuvring speed, armour thickness etc.

The weight of armour in combat vehicles usually gets constrained by the overall weight of the vehicle as well as PWR i.e. power to weight ratio. The combat effectiveness of a tank amongst the three main factors: firepower, protection, and mobility, lays emphasis on firepower but may not remain so in the future when human life will be considered the most precious of all, even in the battlefield. The armour naturally kept pace with the ammunition, partly by increased weight and thickness and partly by increased effectiveness. From the trends in the development of HEAT penetrators shown in the fig. 1 , it is seen that, in general, there has been an increase in the penetration efficacy of HEAT by about $20 \%$ every decade. [1-5].



Fig 1 : Trends in improvement of firepower

Adapted from Madhu \& Bhat [2]

As already discussed, for selecting the main battle tank, various sub-criteria need to be identified and further studied and that is the aim or objective of present research. The research paper is arranged as follows : Section 2 briefly describes the various selection criteria for main battle tank (MBT) selection. Section 3 describes the ISM methodology. Section 4 focuses on ISM application to case example . Finally the observations along with future directions are presented in section 5 . 


\section{LITERATURE REVIEW ${ }^{1-6}$}

Determining the criteria that should be used in MBT selection is of great importance. The criteria should be wisely chosen and structured to allow the investigation of the complex interactions among them. It is important that these criteria should be consistent with the elements of combat power as defined in three primary elements i.e. Mobility , Firepower, Protection/ Survivability . Consequently, in this research, in order to realise the decision goal, at the second phase, through literature review and expert opinions, an attempt has been made to determine various sub-criteria under these categories that can be used in main battle tank selection problem. Though our research is exploratory in nature and is based on the review of literature through databases and search engines such as Google scholar, Research gate , EBSCo etc, The research literature consulted have interviewed the armour Branch Officers as well as under Secretary of Defence Associates having round fifteen years of experience and capable of analysing the land platforms technically. Based on their comments, the prime criteria have been categorised into three basic categories of Mobility, Firepower and Survivability . So as per study, the decision criteria suggested as [6-17] .

Table I: Criteria required for selection of main battle tank selection

\begin{tabular}{|c|c|c|}
\hline & Main criteria & Sub criteria \\
\hline 1 & \multirow[t]{3}{*}{ Mobility } & Maximum speed(MS) \\
\hline & & Power to weight ratio(PWR) \\
\hline & & Fuel consumption rate (FCR) \\
\hline \multirow[t]{4}{*}{2.} & \multirow[t]{4}{*}{ Firepower } & $\begin{array}{c}\text { Main gun effectiveness (MGE)/ heat } \\
\text { effectiveness }\end{array}$ \\
\hline & & Main gun ammunition load (MGAL) \\
\hline & & Fire control system (FCS) \\
\hline & & $\begin{array}{c}\text { Firing range / area (FR) ( short range / } \\
\text { long range ) }\end{array}$ \\
\hline \multirow[t]{5}{*}{3.} & \multirow[t]{5}{*}{$\begin{array}{l}\text { Survivability } \\
\text { / protection }\end{array}$} & $\begin{array}{l}\text { Fire Detection and Supressing Systems } \\
\text { (FDSS) }\end{array}$ \\
\hline & & Laser Warning System (LWS) \\
\hline & & $\begin{array}{c}\text { Ventilating \& Air Conditioning System } \\
\text { (VACS) }\end{array}$ \\
\hline & & Active Protection System (APS) \\
\hline & & $\begin{array}{l}\text { Active armour / Adding armour (AA)/ } \\
\text { Armour thickness }\end{array}$ \\
\hline
\end{tabular}

\section{INTERPRETIVE STRUCTURAL MODELLING METHODOLOGY}

Interpretive structural modelling methodology or ISM [18] is a known technique to map the relationships amongst the relevant elements as per decision maker's problems in a hierarchical manner. Starting with the identification of elements, it proceeds with establishing the contextual relationships between elements (by examining them in pairs ) and move on towards developing the structural selfinteraction (SSIM) matrix using VAXO [18] and then initial reachability matrix and final reachability matrix and rearranging the elements in topological order using the level partition matrices. A Mic-Mac analysis is performed afterwards which categorize the variables as per the driving and dependence power in to autonomous, dependent, driver and linkage category. Finally, a diagraph can be obtained.

\section{DEVELOPMENT OF ISM MODEL : CASE EXAMPLE}

In this section, ISM model is developed for studying the interrelationships amongst various challenges for aerospace and aviation sector of countries like India . About 12 metrics viz. Maximum speed(MS); Power to weight ratio (PWR) ; fuel consumption rate (FCR); Main gun effectiveness (MGE); Main gun ammunition load (MGAL); Fire control system (FCS); Automatic loading system (ALS); Firing area (FA); Anti-tank guided missile capability (ATGMC); Fire Detection and Supressing Systems (FDSS); Laser Warning System (LWS); Ventilating \& Air Conditioning System (VACS); Active Protection System (APS) and Adding armour (AA)/Armour have been identified as mentioned in Table 1 above which will be studied further with the help of ISM methodology . Following is the explanation points on various criteria and their possible relation based on experts discussion. [ Reference from Madhu \& Bhat[1] .

$>$ Armour / armour thickness as well as ammunition and ammunition load depends on power to weight ratio as well as main gun effectiveness and vice versa.

$>$ Combat effectiveness depends on firepower as well as firing range and speed.

$>$ Active protection system depends on laser warning system , fire detection and suppression systems as well as ventilating systems and vice versa.

$>$ There is also the question of affordability in terms of weight. In this connection, it is worthwhile for a moment to consider the competition between protection and mobility.

$>$ The weight of armour in combat vehicles usually gets constrained by the overall weight of the vehicle as well as PWR i.e. power to weight ratio . Increased mobility often demands reduced weight, and hence, sacrifice in protection. But the competition is not that straight forward because increased protection also increases mobility.

$>$ Active armour is likely to emerge as the main mechanism of protection against slow-flying missiles. This may also be extended for protection against fast moving KE shots which is currently under various stages of $R \& D$ the world over.

$>$ The armour naturally kept pace with the ammunition, partly by increased weight and thickness and partly by increased effectiveness. This means that AA is directly related to MGE and MGAL. On the sides and top, the armour should provide a high chance of survival (greater than $85 \%$ ) against contemporary Heat threats with at least $80 \%$ chance of survival against futuristic higher threats possessing $15 \%$ higher penetration capability.

$>$ At a given level of materials technology, there is a certain threshold areal density below which protection falls down exponentially. The threshold 
weight moves to higher weight with advances in ammunition research and to lower weight with advances in armour. In contrast, there is no such catastrophic debilitating effect of decreased mobility at any weight or power/weight ratio. This means weight directly related to ammunition and inversely related to mobility.

$>$ Therefore, all futuristic tanks may contain firepower and protection as the main determinants of vehicle design and be relieved from the grip of power/weight ratio.

$>$ An added envelop of active protection system (APS) on the turret top and sides of hull can reduce the chance of hit by HEAT and other threats.

$>$ As with the MBT, it would be prudent to place less emphasis on mobility to enable creation of an excellent combination of firepower and protection to defeat the enemy and yet remain protected.

$>$ Higher power to weight ratio, higher is the mobility. This means higher protection. This means that FDSS, LWS, VACS, APS could be positively related to PWR .

[ Kindly note that the explanation for the criteria is based on the reference obtained from Bhat and Madhu ( 2011) and author's own perception and experiences. It is subjected to change as per the military warfare situation and demand. This is exclusively for research and education based purpose and not for practical or military purpose ]

\subsection{Construction of Structural self- interaction Matrix (SSIM)}

This matrix gives the pair-wise relationship between two variables i.e. $I$ and $j$ based on VAXO. SSIM has been presented below in Fig 1.

\subsection{Construction of Initial Reachability Matrix and final reachability matrix}

The SSIM has been converted in to a binary matrix called the initial reachability matrix shown in fig. 2 by substituting V, A, $\mathrm{X}, \mathrm{O}$ by 1 or 0 as per the case. After incorporating the transitivity, the final reachability matrix is shown below in the Fig 3.

\begin{tabular}{|c|c|c|c|c|c|c|c|c|c|c|c|c|c|}
\hline S. No. & Barriers & 1 & 2 & 3 & 4 & 5 & 6 & 7 & 8 & 9 & 10 & 11 & 12 \\
\hline & & L & P & FC & M & M & FC & FR & F & LW & V & A & A \\
& & S & W & R & G & G & S & & D & S & A & PS & A \\
& & & & & & A & & & SS & & CS & & \\
\hline 1 & MS & & A & X & X & A & A & A & A & A & A & A & A \\
\hline 2 & PWR & & & X & V & A & O & V & X & X & X & X & X \\
\hline 3 & FCR & & & & X & X & O & X & A & A & A & A & O \\
\hline 4 & MGE & & & & & A & O & X & O & O & O & O & X \\
\hline 5 & MGAL & & & & & & X & V & O & O & O & O & X \\
\hline 6 & FCS & & & & & & & V & V & O & V & V & O \\
\hline 7 & FR & & & & & & & & O & O & O & O & A \\
\hline 8 & FDSS & & & & & & & & & X & X & X & A \\
\hline 9 & LWS & & & & & & & & & & X & X & A \\
\hline 10 & VACS & & & & & & & & & & X & A \\
\hline 11 & APS & & & & & & & & & & & & A \\
\hline 12 & AA & & & & & & & & & & & & \\
\hline
\end{tabular}

Fig 1: SSIM matrix for pair wise relationship amongst barriers

\begin{tabular}{|c|c|c|c|c|c|c|c|c|c|c|c|c|c|}
\hline S. No. & Barriers & 1 & 2 & 3 & 4 & 5 & 6 & 7 & 8 & 9 & 10 & 11 & 12 \\
\hline & & L & PW & FC & M & M & FC & FR & FD & LW & V & AP & A \\
& & M & R & R & G & G & S & & SS & S & AC & S & A \\
& & & & & E & A & & & & & S & \\
\hline 1 & MS & 1 & 0 & 1 & 1 & 0 & 0 & 0 & 0 & 0 & 0 & 0 & 0 \\
\hline 2 & PWR & 1 & 1 & 1 & 1 & 0 & 0 & 1 & 1 & 1 & 1 & 1 & 1 \\
\hline 3 & FCR & 1 & 1 & 1 & 1 & 1 & 0 & 1 & 0 & 0 & 0 & 0 & 0 \\
\hline 4 & MGE & 1 & 0 & 1 & 1 & 0 & 0 & 1 & 0 & 0 & 0 & 0 & 1 \\
\hline 5 & MGAL & 1 & 1 & 1 & 1 & 1 & 1 & 1 & 0 & 0 & 0 & 0 & 1 \\
\hline 6 & FCS & 1 & 0 & 1 & 0 & 1 & 1 & 1 & 1 & 0 & 1 & 1 & 0 \\
\hline
\end{tabular}




\begin{tabular}{|c|c|c|c|c|c|c|c|c|c|c|c|c|c|}
\hline 7 & FR & 1 & 0 & 0 & 1 & 0 & 0 & 1 & 0 & 0 & 0 & 0 & 0 \\
\hline 8 & FDSS & 1 & 1 & 1 & 0 & 0 & 0 & 0 & 1 & 1 & 1 & 1 & 0 \\
\hline 9 & LWS & 1 & 1 & 1 & 0 & 0 & 0 & 0 & 1 & 1 & 1 & 1 & 0 \\
\hline 10 & VACS & 1 & 1 & 1 & 0 & 0 & 0 & 0 & 1 & 1 & 1 & 1 & 0 \\
\hline 11 & APS & 1 & 1 & 1 & 0 & 0 & 0 & 0 & 1 & 1 & 1 & 1 & 0 \\
\hline 12 & AA & 1 & 1 & 0 & 1 & 1 & 0 & 1 & 1 & 1 & 1 & 1 & 1 \\
\hline
\end{tabular}

Fig 2: Initial reachability matrix

\begin{tabular}{|c|c|c|c|c|c|c|c|c|c|c|c|c|c|c|}
\hline S. No. & Barriers & 1 & 2 & 3 & 4 & 5 & 6 & 7 & 8 & 9 & 10 & 11 & 12 & \\
\hline & & $\begin{array}{c}\mathrm{LM} \\
\mathrm{S}\end{array}$ & $\begin{array}{c}\mathrm{PW} \\
\mathrm{R}\end{array}$ & $\begin{array}{c}\mathrm{FC} \\
\mathrm{R}\end{array}$ & $\begin{array}{c}\text { M } \\
\text { GE }\end{array}$ & $\begin{array}{c}\text { MG } \\
\text { AL }\end{array}$ & $\begin{array}{c}\text { FC } \\
\text { S }\end{array}$ & FR & $\begin{array}{l}\text { FD } \\
\text { SS }\end{array}$ & $\begin{array}{c}\text { LW } \\
\text { S }\end{array}$ & $\begin{array}{l}\text { VA } \\
\text { CS }\end{array}$ & $\begin{array}{c}\text { AP } \\
\text { S }\end{array}$ & AA & $\begin{array}{l}\text { D. } \\
\text { P }\end{array}$ \\
\hline 1 & MS & 1 & 0 & 1 & 1 & 0 & 0 & 1 & 0 & 0 & 0 & 0 & 1 & 5 \\
\hline 2 & PWR & 1 & 1 & 1 & 1 & 1 & 0 & 1 & 1 & 1 & 1 & 1 & 1 & 11 \\
\hline 3 & FCR & 1 & 1 & 1 & 1 & 1 & 1 & 1 & 1 & 1 & 1 & 1 & 1 & 12 \\
\hline 4 & MGE & 1 & 1 & 1 & 1 & 1 & 0 & 1 & 1 & 1 & 1 & 1 & 1 & 11 \\
\hline 5 & MGAL & 1 & 1 & 1 & 1 & 1 & 1 & 1 & 1 & 1 & 1 & 1 & 1 & 12 \\
\hline 6 & FCS & 1 & 1 & 1 & 1 & 1 & 1 & 1 & 1 & 1 & 1 & 1 & 0 & 11 \\
\hline 7 & FR & 1 & 0 & 1 & 1 & 0 & 0 & 1 & 0 & 0 & 0 & 0 & 1 & 5 \\
\hline 8 & FDSS & 1 & 1 & 1 & 1 & 1 & 0 & 1 & 1 & 1 & 1 & 1 & 0 & 10 \\
\hline 9 & LWS & 1 & 1 & 1 & 1 & 1 & 0 & 1 & 1 & 1 & 1 & 1 & 0 & 10 \\
\hline 10 & VACS & 1 & 1 & 1 & 1 & 1 & 0 & 1 & 1 & 1 & 1 & 1 & 0 & 10 \\
\hline 11 & APS & 1 & 1 & 1 & 1 & 1 & 0 & 1 & 1 & 1 & 1 & 1 & 0 & 10 \\
\hline \multirow[t]{2}{*}{12} & AA & 1 & 1 & 1 & 1 & 1 & 1 & 1 & 1 & 1 & 1 & 1 & 1 & 12 \\
\hline & De.P & 12 & 10 & 12 & 12 & 10 & 4 & 12 & 10 & 10 & 10 & 10 & 7 & \\
\hline
\end{tabular}

Fig 3 : Final reachability matrix

D.P : Driving power ; De.P : dependence power

\subsection{Level Partition}

From the final reachability matrix, reachability and final antecedent set for each factor are found. The elements for which the reachability and intersection sets are same are the top-level element in the ISM hierarchy. After the identification of top level element, it is separated out from the other elements and the process continues for next level of elements. Reachability set, antecedent set, intersection set along with different level for elements have been shown below in table 1 .

Table 1: Iteration

\begin{tabular}{|c|c|c|c|c|}
\hline $\begin{array}{c}\text { S. } \\
\text { No } \\
\cdot\end{array}$ & $\begin{array}{c}\text { Reachability } \\
\text { set }\end{array}$ & $\begin{array}{c}\text { Antecedent } \\
\text { set }\end{array}$ & $\begin{array}{c}\text { Intersect } \\
\text { ion set }\end{array}$ & Level \\
\hline $\mathbf{1 .}$ & $1,3,4,7$ & $\begin{array}{c}1,2,3,4,5,6,7,8 \\
9,10,11,12\end{array}$ & $\mathbf{1 , 3 , 4 , 7}$ & I \\
\hline 2. & $\begin{array}{c}1,2,3,4,5,7,8, \\
9,10,11\end{array}$ & $\begin{array}{c}2,3,4,5,6,8,9,1 \\
0,11,12\end{array}$ & $\begin{array}{c}\mathbf{2 , 3 , 4 , 5 , 8 ,} \\
\mathbf{9 , 1 0 , 1 1}\end{array}$ & II \\
\hline 3. & $\begin{array}{c}1,2,3,4,5,7,8, \\
9,10,11,12\end{array}$ & $\begin{array}{c}1,2,3,4,5,12 \\
\mathbf{1 2}\end{array}$ & $\mathbf{1 2}$ & III \\
\hline 4. & $\begin{array}{c}1,2,3,4,5,6,7, \\
8,9,10,11,12\end{array}$ & $3,5,6,12$ & $\mathbf{6}$ & IV \\
\hline
\end{tabular}

\subsection{Classification of factors}

The critical success factors described earlier are classified in to four clusters viz. autonomous factor, dependent factors, linkage factors and independent / Driving factors are mentioned below.

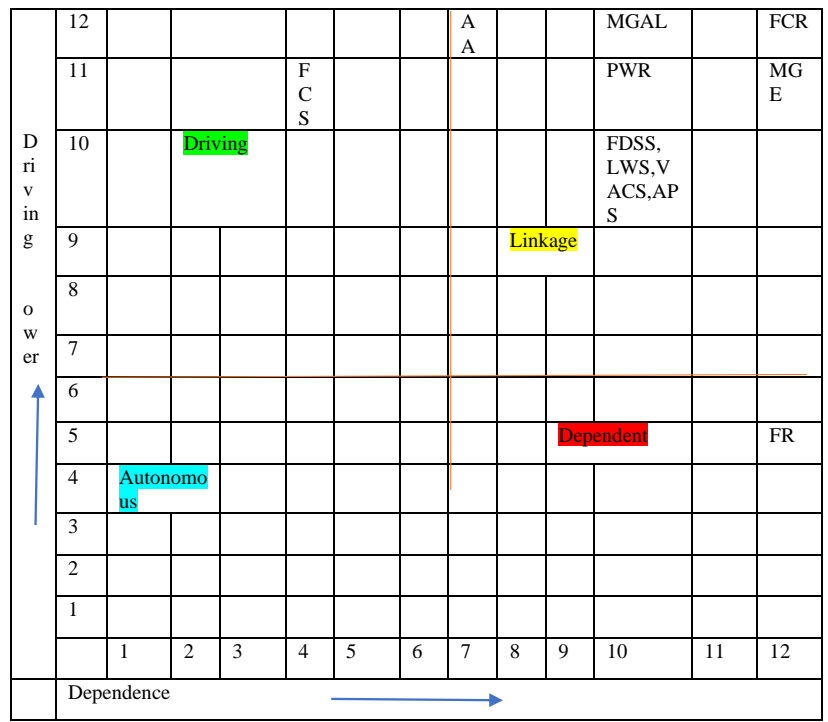

Fig. 4.Driving Power and Dependence Diagram 


\section{LITERARY OBSERVATIONS}

This section concludes with some of the literary observations that could be helpful to reader

- As the financial budgets are limited, defence contractors are expanding their reach into new geographies either through DoD-led foreign military sales or, increasingly, through direct commercial sales. For others, it has meant adapting their current products and capabilities for use in civilian and commercial settings in order to capture adjacent vertical markets.

- The more forward-looking organizations, however, are now taking steps to fully rethink their portfolio of products and services and, in doing so, are developing and/or acquiring new capabilities in key growth areas such as cybersecurity, data management, mission software development, and underperforming assets.

- With the changing market dynamics towards leaner development cycles, lower manufacturing and manageable costs and faster speed, it is required from the established and veteran defence players to have good repo' with the new entrants as well .

- $\quad$ Finally, from adapting products to adjacent markets and building new partnerships with non-traditional players such as technology providers, the defence sector is undergoing an era of convergence.

\section{ACKNOWLEDGMENTS}

Our thanks to the anonymous reviewers whose comments have helped us in improving the manuscript. The authors are thankful to the Defence Research and Development Organisation, Delhi, India for the motivation to conduct this research . Co-author Remica Aggarwal also pay her sincere regards to Prof. S.P Singh of DMS, IIT Delhi for disseminating he knowledge about ISM methodology.

\section{REFERENCES}

[1] Madhu, V. and Bhat, T.B. 2011. Armour Protection and Affordable Protection for Futuristic Combat Vehicles, Defence Science Journal, 61(4), 394-402.

[2] Bhat, T.B.; Madhu, V. \& Gupta, N.K. 2007. Perspectives in armour materials and designs. Indian National Academy of Engineers, IIT Delhi, New Delhi.

[3] Rust, Michael.2010. Passive protection concepts. In IBD Deisenroth Engineering, Eurosatory, 33-37.

[4] Madhu, V. 2010 . Advanced armour materials and technologies for battlefield systems. In International Conference on Armoured Vehicles India, New Delhi, India.
[5] Army Materials Research: Transforming land combat through new technologies. AMPTIAC Quarterly, 2004, $8(4), 1-130$

[6] NATO, Future of Armoured Forces, NATO Army Armaments Group. November 2002.

[7] Ogorkiewicz, R.M. 2002. The Outlook for Tanks. International Defense Review, 41-44.

[8] Foss, C.F. 2013. Armoured Shift. Jane's Defence Weekly, 22-27.

[9] Hornback, P. 1998.The Wheel Versus Track Dilemma. Armor Magazine, 33-34.

[10] Anthony, H.M. 2012. Close Combat Vehicle and Leopard 2 Main Battle Tank: Back In The Heavyweight Fight. Master of Defence Studies, Canadian Forces College.

[11] Dağdeviren, M.; Yavuz, S. \& Kılınç, N. 2009.Weapon selection using the AHP and TOPSIS methods under fuzzy environment. Expert Syst. Appl., 36(4), 81438151. doi: 10.1016/j.eswa.2008.10.016

[12] Lee, J.; Kang, S.-H.; Rosenberger J. \& Kim, S.B. 2010 A hybrid approach of goal programming for weapon systems selection. Comput. Ind. Eng., 58(3), 521-527. doi: 10.1016/j.cie.2009.11.013

[13] Gupta, R. \& Bhushan, N.1996. Performance evaluation of battle tanks. Def. Sci. J., 46(2), 115-119. doi: $10.14429 /$ dsj. 46.4058

[14] Cheng, C.-H. \& Lin, Y. 2002. Evaluating the best main battle tank using fuzzy decision theory with linguistic criteria evaluation. Eur. J. Oper. Res., 142(1), 174-186. doi: 10.1016/S0377-2217(01)00280-6

[15] Yong, D. \& Cheng, S. 2006. Evaluating the main battle tank using fuzzy number arithmetic operations. Def. Sci J., 56(2), 251-257. doi: 10.14429/dsj.56.1887

[16] Jiang, J.; Li, X.; Zhou, Z.-J.; Xu, D.-L. \& Chen, Y.W.2011. Weapon System Capability Assessment under uncertainty based on the evidential reasoning approach. Expert Syst. Appl., 38(11), 13773-13784. doi: 10.1016/j.eswa.2011.04.179

[17] Defence IQ. Global Armoured Vehicles Market Report 2015. International Armoured Vehicles XV, London, UK, 2014.

[18] Warfield , J.N. 1974. Developing interconnection matrices in Structural Modeling ,. IEEE Transactions on System , Man , and Cybernetics , SMC-4(1) , 81-87. 